\title{
Effects of a Math-Science Integrating Woodwork Play Program on Young Children's Mathematical, Scientific, and Creative Abilities
}

\author{
Junhee $\mathrm{Kim}^{1}$, Jihyun $\mathrm{Kim}^{2}$
}

Ph. D., Department of Child Development \& Education, Myongji University, Seoul, Korea ${ }^{1}$

Associate Professor, Department of Child Development \& Education, Myongji University, Seoul, Korea ${ }^{2}$

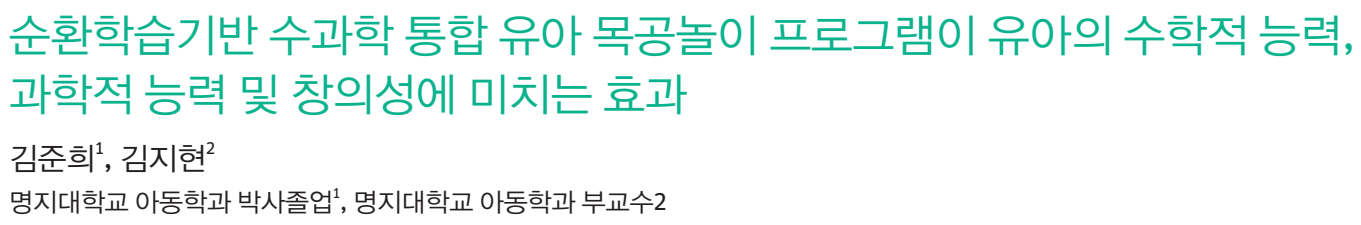

Objectives: This study aims to examine the effects of a math-science integrating woodwork play program, which is based on the learning cycle, on the improvements in young children's mathematical, scientific, and creative abilities.

Methods: Participants were 56 five-year-old children from two classes in M kindergarten located in S city. Only the experimental group participated in the math-science integrating woodwork play program. Data were analyzed using SPSS 21.0. An independent-samples $t$-test and a paired-samples $t$-test were utilized for examining the homogeneity between the experimental and the comparison groups, as well as the effectiveness of the program.

Results: The findings suggest statistically significant differences in the subfactor scores that of measured mathematical abilities, scientific abilities, and creativity, between the experimental group and the control group after program implementation. Furthermore, the statistically significant differences in the scores before and after the program implementation were specifically found in the experimental group, and not in the control group.

Conclusion: A math-science integrating woodwork play program, based on the learning cycle, has a positive influence on improving young children's mathematical, scientific, and creative abilities. The results of this study can contribute to the dissemination of the math-science integrating woodwork play program. Finally, the significance of this study relates to its discovery of the value in woodwork play in terms of math-science integration and creativity development.

Keywords: woodwork play program, learning cycle, mathematical ability, scientific ability, creativity

\section{Introduction}

4차 산업 혁명 사회로 급변하는 이 시대는 현대 사회의 흐름에 발맞출 수 있는 인재에 관심을 기울이고, 인재를 육성하기 위

Corresponding Author: Jihyun Kim, Associate Professor, Department of Child Development \& Education, Myongji University, 34 Geobukgol-ro, Seodaemun-gu, Seoul, Korea

E-mail: jihyunkim@mju.ac.kr
한 역량 강화에 많은 노력과 시간을 할애하고 있다. 과거와 달 리 지식과 정보가 넘쳐나는 지식의 홍수 속에서 이러한 지식 을 단순히 습득하는 것보다 지식의 형성과 습득과정을 이해하 고, 이를 적합한 상황에 맞추어 적절히 재조직 및 활용할 수 있

(C)The Korean Association of Child Studies

This is an Open Access article distributed under the terms of the Creative Commons Attribution Non-Commercial License (http:// creativecommons.org/licenses/by-nc/4.0) which permits unrestricted noncommercial use, distribution, and reproduction in any medium, provided the original work is properly cited. 
는 독특하고 창의적인 사고의 창출 능력이 필요하다(J. H. Kim $\& \mathrm{Kim}, 2019)$. 이와 같은 사회의 변화는 유아교육·보육 분야 에서도 맥을 같이 하는데, 3-5세 연령별 누리과정(Ministry of Education, Science and Technology [MEST], 2013)에서 제시한 바와 같이 미래사회는 창의력, 비판적 사고, 의사소통 능력, 협 업능력의 핵심역량 $4 \mathrm{C}$ 를 갖춘 융합형 인재를 필요로 한다. 시 대의 변화에 발을 맞추어 우리나라에서는 초.중·고를 대상 으로 한 과학교육종합계획(Ministry of Education, 2016)을 발 표하고 '메이커 활동'과 과학 교육을 접목하면서 '메이커 교육 (maker education)'의 활성화가 시작되었다. 메이커 교육은 학 습자를 창의적 존재로 바라보며(Y.-I. Kim, 2018), 활동 안에서 학습자가 다양한 재료를 활용하여 설계에 의한 결과물을 제작 하고, 이 과정을 통해 얻은 지식, 기술을 다른 사람과 공유하고 소통을 이루는 과정을 다룬다(Kang \& Kim, 2017). 유아보육. 교육 현장도 이와 같은 움직임에 발맞추어 관련 교육과정 및 프로그램 개발·적용이 요구된다.

본 연구에서는 메이커 교육의 차원에서 융합형 인재를 기 르기 위한 요소인 유아의 수학적 능력과 과학적 능력, 그리고 창의성에 주목하고자 한다. 유아는 자신의 내적.외적 산물을 창출해내기 위해 아이디어가 수용되는 환경에서 자발적인 참 여를 통해 다양한 정보를 수집하고, 분류하여 적용하는 수학 적 사고를 활용한다(E. H. Noh, 2008). 또한 문제해결 과정을 공유하고 나누는 경험은 문제에 대한 경향을 파악하게 하고, 결과를 예측할 수 있는 과학적 사고기술을 필요로 한다(Cho, 2015). 이뿐만 아니라 실생활의 경험을 바탕으로 목적을 띄고 생산적인 문제해결을 추구하므로 창의적 문제해결 역량이 요 구된다(J.-H. Kim, 2017).

수학적 능력은 수학적 개념의 발달 정도를 의미하며 수학적 지식과 기술 수행 능력을 포함한다(H.-J. Choi \& Hwang, 2003). 수학은 유아의 인지구조와 학습 가능성과 연관된 중요한 영역 이며(H.-J. Choi \& Lee, 2005), 다른 교과의 학습에도 영향을 미 치는 도구적 교과이기 때문에(H. S. Choi \& Hwang, 2010) 유아 기의 수학적 능력 발달은 중요한 과업이다. 그러므로 수학적 능력의 증진을 위해 구체적인 사물을 통해 수학적 사고를 활용 할 기회를 제공해야 하며, 일상생활에서도 수학적 능력을 적용 해 볼 수 있는 교육과정의 수립과 운영이 필요하다.

과학적 능력은 유아가 직접적인 경험을 통해 습득한 정보 를 통해 일상의 다양한 문제 상황을 대처하는데 필요한 사고 기술이다(Martin, 2012). 과학적 능력은 관찰하기, 분류하기, 추론하기, 측정하기, 의사소통하기의 탐구과정기술을 사용하 는 능력이 포함된다(Cho, 2015). 과학적 능력은 과학 현상에
대한 지속적인 호기심을 가지고, 자발적으로 문제해결을 위한 시행착오의 과정을 통해 발달하므로 주변 사물과 자연환경에 호기심을 가지고 능동적으로 탐구하며, 문제해결을 위한 다양 한 아이디어 적용과 해결 과정의 경험은 유아가 세상에 대한 지식을 배울 수 있는 매우 중요한 경험이다(MEST, 2013). 그 러므로 유아기 과학적 능력발달을 위해서는 스스로 탐구할 수 있는 환경에서 문제 상황에 대한 지속적인 호기심과 관찰을 통해 다양한 해결방안을 모색해 볼 수 있는 경험과 이를 다른 사람들과 공유해 볼 기회가 필요하다.

창의성은 사회적으로 가치가 인정될 만한 산출물을 생산하 고, 다양한 문제 상황을 해결하기 위한 새로운 의견을 도출할 수 있는 유창성, 융통성, 독창성 및 상상력의 능력이 포함된다 (Jeon, 2000). 인간의 수렴적 사고와 확산적 사고의 지적 구조 모형을 제시한 Guilford (1968)는 이 중 확산적 사고를 창의성 과 관련된 능력으로 보았으며, Torrance (1963)는 창의적 사고 란 지식의 부족과 방해 요소 등을 인식하고, 원인에 대한 가설 을 통해 이를 검증하며 수정과 재검증의 과정을 통해 최종적 인 결과를 전달하는 것이라고 주장하였다. 즉, 유아기는 창의 적 사고와 상상력이 발달하는 중요한 시기이므로 풍부한 환경 에서 자발적으로 새로운 지식을 구성해 볼 기회는 매우 중요 하다(Torrance, 1963). 그러므로 수학적 능력과 과학적 능력 및 창의성은 미래 인재를 위한 핵심역량임과 동시에 메이커 교육 의 중요한 요소이므로(Y.-I. Kim, 2018), 유아보육·교육현장에 서는 관련 요소들이 포함된 유아 주도의 교육프로그램 계획과 적용이 요구된다.

3-5세 연령별 누리과정(MEST, 2013)은 유아의 전인발달과 효과적인 학습을 위해 통합적 교육과정 운영을 권고하였다. 구성주의 측면에서 살펴보면 유아는 주변 환경을 탐색하는 과 정에서 환경을 구체적으로 조작하고 내적으로 추상하며 지식 을 통합적으로 구성한다(Hong, 2005). 수·과학적 탐구과정을 통해 논리적 사고를 신장하고, 이는 일상의 문제를 논리적이 며 합리적으로 해결하는 능력의 토대가 된다(MEST, 2013). 수 학은 주변 세계를 탐색하고 지식을 확장하기 위해 사용되는 또 다른 언어로 사용되는 의사소통 체계이므로(Usiskin, Reys, \& Reys, 2014), 과학 학습에 적용될 수 있는 의사소통 매체의 역할을 한다. 이중 과정적 기술인 분류하기, 비교하기, 순서짓 기, 의사소통하기, 측정하기, 자료수집하기, 추론하기 등은 수 학과 과학 학습에 공통으로 필요한 요소이며, 수학과 과학은 인지발달에 동시에 영향을 미치므로(J. H. Kim \& Kim, 2018), 사물이나 자연적 환경을 다루는 과정에서 자연스럽게 통합적 으로 적용될 수 있다(Martin, 2012). 그러므로 활동 제공 시 유 
아 주도적인 탐구학습을 통해 수학과 과학 교과의 통합뿐만 아니라 활동 내용 안에 자연스러운 과정의 통합이 이루어지 도록 해야 한다(S. S. Han \& Bae, 2004). 또한 3-5세 연령별 누 리과정은 유아의 자율적이고 창의적인 역량을 강조하면서 창 의성 발달에 초점을 맞추어 교육과정을 운영하도록 제시하였 다(MEST, 2013). 그러므로 유아보육·교육기관에서는 유아 발 달에 적합한 교육과정 운영을 통해 수학적 능력과 과학적 사 고과정을 증진 시키고, 이를 일상생활에 활용할 기회를 제공 하며, 사회·문화에서 가치를 부여할만한 사물이나 아이디어를 창출할 수 있는 활동이나 상황을 제시하여 유아의 창의성 향 상을 도모해야 한다.

수학과 과학 통합 활동에 대한 선행 연구들을 살펴보면 수학과 과학이 통합된 프로그램은 수학적 능력 및 태도(S. J. Kim, 2001; Koo, 2007; E. J. Lee, 2010; Yun, 2005) 과학적 탐구 능력 및 태도(S. J. Kim, 2001; Koo, 2007; Yun, 2005), 그리고 창 의적 사고(Kaon \& Park, 1997)의 발달에 효과가 있었다. 그러 나 선행연구에서는 수학과 과학 통합 프로그램의 효과를 수학 또는 과학의 각 영역의 능력이나 태도의 변화만을 살펴보거나 각 영역 내에서도 특정 능력(예: 수와 연산, 측정, 공간 능력)에 서의 효과만을 다루는 것이 대부분이었다. 또한 유아보육-교 육기관의 수학과 과학 통합 활동 운영은 과정의 통합보다는 한 활동을 중심으로 다른 교과 내용이 포함되도록 계획되며, 교사가 주도하는 방식의 수업이 대부분이기 때문에 유아의 발 달에 적합하고 수학과 과학의 전반적인 영역의 통합을 이룰 수 있는 유아 주도적인 교수학습방법 적용 연구가 필요하다 (Yun, 2005).

본 연구에서는 수학과 과학을 통합적으로 적용할 수 있고, 유아가 자신만의 산물 창출을 통해 창의적인 사고를 증진 시 킬 수 있는 맥락으로 목공놀이를 접목하고자 하였다. 목공놀 이는 다양한 물체의 물리적 특성과 차이점을 탐색함으로써 유 아의 집중력과 수개념을 향상하며, 과학적 사고력을 촉진한다 는 점(H. N. Park, 2010)에서 수학과 과학통합 프로그램의 맥락 으로 적절하다. 유아들은 발달 특성상 실물을 직접 조작하면 서 경험을 구축하는 특성이 있어, 구체물과 실제 상황이 포함 되었을 때 학습이 이루어진다(Hong, 2004). 이에 자연환경이 나 실물자료들은 수학과 과학 학습의 상황적 맥락을 제공하고 탐구과정의 기술 적용이 용이하다. 목공활동은 가공이 용이 한 소재를 다루는 활동이기 때문에 자신의 생각과 느낌을 자 발적이고, 창의적으로 표현하는 사고력을 길러주어 통합 교육 에 적합하며(Hwang, 2003; Y.-I. Kim, 2009), 관계적 사고력 및 수개념(Skeen \& Anita, 1984)과 공간능력 및 공간 지각력 발달
에 긍정적인 효과가 있다(Bae, 2010; J. H. Kim, 2017; Y. H. Lee \& Won, 2010; H. N. Park, 2010). 이처럼 다양한 교육적 효과를 보여주는 목공활동은 유아보육·교육 현장에서 계획·실행되 고 있는 다양한 영역의 활동처럼 규칙적이고 꾸준하게 제공되 어야 교육적 효과를 얻을 수 있다(Abraham, 2011). 선행연구에 서 알 수 있듯이 기존 목공놀이 연구에서 나타나는 유아의 발 달에 긍정적인 측면도 상당 부분 있으나 면밀히 살펴보면, 기 존 연구에서 실시된 목공놀이 활동은 단순히 목공의 기능적인 측면을 반복해서 익히는 활동이거나, 회기별로 단위 활동이 나열되는 방식으로 유기적인 연계성 없이 진행되어 수학과 과 학 통합 활동의 맥락으로 적절하지 못하고, 문제 상황을 해결 하기 위한 반복적인 시도나 적용의 과정을 경험할 수 있는 내 용이 다소 부족하였다(Go \& Shin, 2011). 또한 유아 스스로 탐 구하는 과정이나 자발적인 탐색 과정이 포함된 활동보다는 교 사가 주도하는 활동이었기 때문에(H. N. Park, 2010), 유아가 주도적으로 재료를 이용하여 자신만의 생각을 창의적으로 표 현하여 구성물을 창출하기에는 다소 어려움이 있었다. 더불어 기존 연구들에서는 대부분 목공놀이를 실외놀이로 국한하여 운영되었는데, 유아보육·교육기관에서는 목공놀이를 실내 및 실외 흥미영역으로 배치하여(Kaon, 1999), 유아가 스스로 문제 상황에 대한 다양하고 창의적인 대안을 모색하고 이를 일상 생활에 적용할 수 있는 교육과정의 계획·운영이 필요하다. 이 처럼 선행 목공놀이 연구의 한계점을 극복하여 유아가 스스로 문제 상황에 호기심을 가지고 주도적으로 해결방안을 탐구하 고, 이러한 과정에서 수학과 과학이 통합될 수 있는 교수학습 방법을 적용한 목공놀이 프로그램 개발이 요구된다.

선행연구들을 통해 목공놀이는 유아 발달에 긍정적인 측면 이 많이 있음을 확인할 수 있었으나, 구성물을 만드는 것에만 초점을 두었을 뿐 그 과정에서 유아 주도성이나 창의성을 중 점적으로 다루는 탐구 지향적인 과정을 찾아보기 어려웠다. 즉, 메이커 교육의 관점과 같이 유아를 창조적이고 주도적인 주체로 바라볼 때 유아는 문제해결을 위한 탐구과정을 경험할 수 있다는 점에서 수학적 능력과 과학적 과정기술 활용하기에 기초를 둔 탐구 지향적 과정의 경험은 매우 중요하다. 유아 주 도의 탐구학습이 이루어질 수 있는 교수학습방법을 적용한다 면 수과학 통합 유아 목공놀이 프로그램을 통한 수학적 능력, 과학적 능력 및 창의성 발달에 대한 목표 성취의 가능성을 높 일 수 있을 것이다.

이에 본 프로그램 개발을 위해 순환학습모델(Gallenstein, 2003)을 도입하고자 한다. 순환학습모델은 학습자가 주체가 되어 구체적인 경험을 통해 스스로 지식을 구성하며, 학습 단 
계의 순환과 반복으로 이루어지는 교수학습 모델이다(S. H. $\mathrm{Kim}, 2015)$. 유아를 대상으로 하는 Gallenstein (2003)의 5E 순 환학습모델은 참여-탐색-설명-확장-평가의 단계가 반복적 으로 순환하는 구조이며, 각각의 단계는 유아의 주도적인 탐 구가 가능하도록 한다. 탐구란 필요한 것을 조사하여 찾아내 거나 얻어내는 것으로 관심거리를 깊이 있게 파고들어 연구하 는 것을 의미한다(Cho, 2015). 또한 학습 단계가 순환적으로 반복되기 때문에 지식의 구성과 더불어 구성한 지식을 적용하 는 과정을 경험하는데 특징이 있다(I. J. Oh \& Kim, 2019). 순 환학습모델을 활용한 수과학 통합 유아 목공놀이 프로그램은 유아 스스로 교사가 제공한 재료를 탐색하고, 자신이 만들고 싶은 구성물을 설계하며, 이에 따라 구성물을 만들어 보는 과 정에서 연관된 지식을 습득하여 이를 다음 세트의 구성물 제 작에 반영하거나 일상에 활용할 수 있도록 한다. 또한 구성물 을 만드는 과정을 친구나 다른 사람들에게 소개하고, 공유하 는 시간을 통해 자신의 놀이 과정을 평가하고 이를 다음 활동 에 수정-보완할 수 있도록 한다. 이처럼 반복적이고 순환적인 과정은 유아에게 자연스러운 수학과 과학의 과정적 통합과 창 의적 문제해결의 경험을 제공하여 결과적으로 유아의 수학적 능력, 과학적 능력 및 창의성 증진을 도모할 것이다. 이와 같은 과정은 창의적인 학습자가 실물을 활용하여 결과물을 제작하 여 지식을 얻고, 이 과정에서 얻은 지식과 기술을 다른 사람과 함께 공유하는 메이커 교육의 과정(Kang \& Kim, 2017)과 맥을 함께 하므로 관련 교육 사례로 활용될 수 있을 것이다.

따라서 본 연구의 목적은 순환학습기반 수과학 통합 유아 목공놀이 프로그램을 만 5세 유아들에게 적용하여 유아의 수 학적 능력과 과학적 능력 및 창의성 발달에 긍정적인 효과가 있는지를 살펴보는 것이다. 결과적으로 본 연구는 유아 발달 에 적합한 교수학습방법을 목공놀이에 적용하여, 미래사회의 주체인 유아들이 주도적으로 문제에 대한 대안을 모색하고 타 인과 소통할 수 있는 창의적인 주체로서의 역량을 증진하기 위한 교육과정 운영에 기여할 것이다.

이와 같은 연구목적에 따라 선정된 연구문제는 다음과 같다.

\section{연구문제 1}

순환학습기반 수과학 통합 유아목공놀이 프로그램은 유아의 수학적 능력 증진에 유의한 효과가 있는가?

\section{연구문제 2}

순환학습기반 수과학 통합 유아목공놀이 프로그램은 유아의 과학적 능력 증진에 유의한 효과가 있는가?

\section{연구문제 3}

순환학습기반 수과학 통합 유아목공놀이 프로그램은 유아의 창의성 증진에 유의한 효과가 있는가?

\section{Methods}

\section{연구대상}

본 연구는 $\mathrm{S}$ 시에 위치한 $\mathrm{M}$ 유치원 만 5세 유아 총 56명을 연구 대상으로 선정하였다. 두 학급은 부모의 사회적 배경, 지역사 회 문화 및 교육경험 등이 유사하며, 하루일과 운영 및 교사 구 성 비율이 동일하였다. 단, 실험집단인 J학급 교사의 교육경력 은 4년 3 개월이고, 통제집단인 $\mathrm{G}$ 학급 교사의 교육경력은 18 년 3개월로, 교사의 교육경력이 프로그램에 영향을 미칠 것 을 고려하여, 교육경력이 20년 3개월인 연구자가 직접 실험집 단인 J학급에서 프로그램을 실시하였다. 실험집단은 만 5세 J 반 28명, 통제집단은 만 5세 $\mathrm{G}$ 반 28명으로 집단별 유아의 성 별 및 평균 월령은 Table 1과 같다. 전조작기인 만 5세를 연구 대상으로 선정한 이유는 구체적인 경험을 통해 새로운 지식 을 구성하여 인지발달을 이루고, 타인의 생각을 조망할 수 있 는 능력이 발달하는 시기이기 때문이다(Piaget, 1964). 이뿐만 아니라 타인과의 사회적 관계에 기초가 되는 의사소통 발달이 가장 활발하게 이루어지며(Kwon \& Hwang, 2013), 창의적 상 상력과 창의적 사고가 발달하는 적기이다(Torrance, 1963). 더 불어 창의성 검사(Torrance Tests of Creative Thinking [TTCT]) 를 실시할 경우 성인의 지시를 이해하고 적절한 반응을 보이 기에 만 4세 이후가 적합하기 때문이다. 이에 연구의 대상인 만 5세 유아의 발달에 기초하여 프로그램을 개발 시 유아 스스 로 재료를 탐색하여 구성물을 만들고, 다양한 문제 상황에 대 한 다양한 대안을 모색해 보며, 이 과정을 또래와 함께 공유하 여 타인과의 의견 교환을 통해 자신의 구성물에 대한 평가와 반영이 이루어지도록 구성하였다. 본 연구에서는 유아의 수학 적 능력과 지능의 관련성(J. H. Kim \& Kim, 2018)을 고려하여

Table 1

Mean Age and Standard Deviations of Experimental Group and Control Group

\begin{tabular}{lccccc}
\hline \multicolumn{1}{c}{ Group } & Boy & Girl & Total & $M$ (months) & $S D$ \\
\hline Experimental group & 15 & 13 & 28 & 70 & 3.40 \\
Control group & 15 & 13 & 28 & 69 & 3.01 \\
\hline Note. $N=56$. & & & & &
\end{tabular}


그 영향력을 통제하고자 Mun (2014)이 한국판으로 표준화한 Kaufman Assessment Battery for Children, II (K-ABC II )을 사용 하여 측정한 후 70 이상 129 이하 범위의 유아들만 연구대상 으로 선정하였다.

\section{연구도구}

순환학습기반 수과학 통합 유아 목공놀이 프로그램이 유아의 수학적 능력, 과학적 능력 및 창의성에 유의한 효과가 있는지 분석하기 위해 유아그림수학능력 검사, 과학적 탐구능력 검 사, TTCT 도형검사 A, B형을 사용하였다.

\section{수학적 능력}

본 연구에서는 유아의 수학적 능력을 측정하기 위해 Choi와 Hwang (2007)이 개발한 유아그림수학능력 검사를 사용하였 다. Choi와 Hwang (2007)의 검사도구에서 제외된 확률과 통계 영역은 E.-Y. Lee (2010)의 도구를 사용하였다. 유아그림수학 능력 검사의 하위요인별 문항을 살펴보면 대수 영역은 분류(6 문항), 패턴(6문항), 관계(2문항)로 총 14 문항, 수와 연산영역 은 수개념(10문항), 수와 연산(8문항)으로 총 18 문항, 기하 영 역은 도형(7문항), 공간(7문항)으로 총 14 문항, 측정 영역은 시 간(7문항), 측정(7문항)으로 총 14 문항이며 총 60 문항으로 구 성되어 있다. 확률과 통계영역은 총 11 문항으로 자료해석(7문 항), 확률(4문항)의 하위요소로 구성되어 있다. 따라서 본 연구 에서는 총 71 문항으로 구성된 검사 도구를 사용하였다. 검사 방법은 검사자가 개별적으로 유아에게 그림 자료를 제시하고 지시문을 읽어주면 유아는 그림을 보면서 응답하는 형식으로 예를 들어 “곰돌이가 네 마리 있는 그림은 어떤 것이지?", "나 무에서 가장 멀리 있는 아이는 누구일까?” 등의 지시문을 읽어 준다. 소요시간은 25-30분 정도이며, 유아가 문항에 대한 정답 을 말하면 1 점, 그렇지 못할 경우 0 점으로 측정한다. 전체 점 수의 범위는 0-71점이며, 점수가 높을수록 수학적 능력이 높 음을 의미한다. 본 도구의 신뢰도(Cronbach's $\alpha$ )는 대수 .88 , 수 와 연산 .87 , 기하 .88 , 측정 .84 , 확률과 통계 .88 로 양호하였다.

\section{과학적 능력}

본 연구에서는 유아의 과학적 능력을 측정하기 위해 Cho (2015)가 개발한 과학적 탐구능력 검사 도구를 사용하였다. 이 검사는 관찰하기(4문항), 분류하기(3문항), 측정하기(5문항),
추론하기(4문항), 예측하기(4문항), 의사소통하기(4문항)의 6 개 하위요인 총 24 문항으로 구성되어 있다. 검사자가 유아에 게 하위요인별 그림을 보여주며 예를 들어 "이 그림에서 보이 는 것을 이야기해 줄 수 있니?”, “이 그림들을 나눈다면 어떻게 나누고 싶니, 또 다른 방법으로 나누어 보겠니?”, "이 그림 다 음에는 어떤 일이 일어날까?” 등의 질문에 유아가 대답하는 형 식으로 대답을 상, 중, 하로 나눈다. 정답을 맞히고 과학적으로 타당한 이유를 설명할 경우 상, 이유를 설명하나 과학적이거나 논리적이지 않을 경우 중, 반응이 없거나 오답하는 경우 하로 구분하고, 각각 3점, 2점, 1점으로 문항 당 점수를 부여하여, 문 항별로 합산하여 전체 점수를 산출한다. 소요시간은 20-25분 정도이며, 본 연구자가 유아를 개별적으로 주어진 기준에 따라 최대한 객관적으로 평정하였다. 전체 점수의 범위는 24-72점 으로 점수가 높을수록 과학적 능력이 높음을 의미한다. 본 도 구의 하위요인별 신뢰도(Cronbach's $\alpha$ )는 관찰하기 .82 , 분류하 기 .82 , 측정하기 .83 , 추론하기 .83 , 예측하기 .82 , 의사소통하기 .82 이며, 전체 신뢰도(Cronbach's $\alpha$ )는 .83로 양호하였다.

\section{창의성}

본 연구에서 유아의 창의성 검사는 Torrance (1974)가 제작한 TTCT를 Y. C. Kim (1999)이 번역한 도형검사를 사용하였다. TTCT는 동형검사로 A형과 B형으로 구분되며, 본 연구의 사 전검사에 도형 $\mathrm{A}$ 형, 사후검사에는 도형 $\mathrm{B}$ 형으로 실시하였다. TTCT 도형검사는 그림구성하기, 불완전한 도형 완성하기, 선(A형)/원(B형) 구성하기의 3 개의 소검사로 이루어져 있으 며, 하위요인은 유창성, 독창성, 제목의 추상성, 정교성, 성급 한 폐쇄에 대한 저항 그리고 창의적 강점이다. 소검사마다 검 사방법을 유아에게 안내하고 예를 들어, "이 모양을 이용하여 무엇을 만들 수 있을까?”, “무엇을 만들든지, 너희 생각을 마 음껏 그리면 돼." "다양한 선들이 있지, 선을 이용해서 그림을 완성하면 돼." 등의 안내를 하며 검사를 실시한다. 소요시간은 소검사 당 10 분이며, 4 명의 유아를 동시에 분리된 공간에서 검사하였다. 본 도구의 신뢰도(Cronbach's $\alpha$ )는 유창성 .88, 독 창성 .88 , 제목의 추상성 .90 , 정교성 .88 , 성급한 종결에 대한 저항 .88 , 창의적 강점 .89 이며, 전체 신뢰도(Cronbach's $\alpha$ )는 .87로 양호하였다.

\section{지능}

유아의 수학적 능력 및 과학적 능력은 지능과 관련이 있음에 
도 불구하고(J. H. Kim \& Kim, 2018) 수학적, 과학적 능력 및 창의성에 대한 유아 대상의 다양한 선행 프로그램 연구들은 지능의 영향력을 통제하지 못하여 프로그램이 수학적 능력, 과학적 능력 및 창의성에 미치는 온전한 효과를 검증하기에 한계가 있었다. 이에 본 연구에서는 지능의 영향력을 통제하 고자 지능을 측정하였다.

유아의 지능은 한국판으로 표준화한 K-ABC II 를 사용하여 측정하였다(Mun, 2014). 본 도구는 아동과 청소년(만 3세 18 세)을 대상으로 하여 정보처리와 인지발달을 측정할 수 있는 개인지능검사이다. 본 도구의 4 개의 하위척도와 10 개의 하위 검사로 수회생, 단어배열, 빠른 길 찾기의 순차처리, 관계유추, 삼각형, 형태처리의 동시처리, 이름기억, 암호해독의 학습력, 표현어휘, 수수께끼의 지식이다. $\mathrm{K}-\mathrm{ABC} I \mathrm{I}$ 는 정답보다는 정답 산출 과정에 초점을 맞춘 문제해결 능력으로써 순차처리, 동 시처리를 측정하고, 기관이나 가정에서 얻은 지식을 측정하는 지식 영역 및 주어진 정보를 학습하는 능력의 정도를 측정하 는 학습력을 총체적으로 파악하기에 적합한 도구이다. 검사자 는 지침에 따라 질문을 하고, 검사 과정에서 4 회 이상 대답을 하지 못하면 해당 문항을 중단하였으며 응답이 정답이면 1점, 오답이나 무답은 0 점으로 처리였다. 실시된 하위검사 점수는 하위척도별로 합산하고 환산점수를 확인하여 표준점수로 나 타냈다. 소요시간은 30 분 정도였으며, 전체 신뢰도 Cronbach's $\alpha$ 는 .89이었다.

지능을 통제하기 위해 지능의 표준점수의 범위에 따라 분 석대상을 선정하였다. 지능의 표준점수의 범위는 69 이하는 아주 낮은, 70-79는 다소 낮은, 80-89는 낮은, 90-109는 보통, 110-119는 높은, 120-129는 다소 높은, 130 이상은 아주 높은 으로 정해져 있으며, 본 연구 대상자 중 지능점수가 아주 낮은 점수(69 이하)와 아주 높은 점수(130 이상)는 존재하지 않고 56명 모두 70 이상 129 이하 범위 내에 있어 제외할 대상자는 없었다.

\section{연구절차}

\section{예비조사}

본 연구에서 개발한 순환학습기반 수과학 통합 유아 목공놀이 프로그램이 수학적 능력, 과학적 능력, 창의성에 미치는 효과 검증과 지능점수를 통제하기 위해 선정한 측정도구의 적절성 을 평가하고자 2018년 2월 6일 2월 8일까지 S시에 위치한 유 치원 만 5 세 남녀 각 2 명씩, 총 4 명을 대상으로 예비조사를 실
시하였다. 연구도구에 대한 문항의 이해도와 검사 소요시간 등의 적절성을 알아보았으며, 각 도구별 검사 소요시간 및 방 법에 있어 문제점이나 어려움은 발견되지 않았다. 단, 유아에 게 4 개의 검사를 해야 하므로 검사도구 순서에 따른 효과를 방 지하고자 유아마다 검사도구 순서를 다르게 하였다.

\section{검사자 훈련}

유아의 수학적 능력, 과학적 능력, 창의성 및 지능 검사에 앞서 검사자의 일관성 있는 검사를 위해 훈련을 하였다. 검사는 독 립된 공간에서 검사자와 유아가 일대일로 하는 검사로, 유아 교육 전공 석사과정 2 인을 대상으로 검사자 훈련을 진행하였 다. 검사자 훈련을 위해 연구자가 각 검사의 문항내용과 검사 매뉴얼을 숙지한 상태에서 예비조사를 하고, 그 과정을 VTR 로 녹화하였다. 검사자 교육은 2018년 2월 3주에 2차시에 걸 쳐 진행되었다.

\section{사전검사}

순환학습기반 수과학 통합 유아 목공놀이 프로그램이 진행되 기 전 사전검사를 하였다. 사전검사는 2018년 4월 2일 4월 27일 사이에 실험집단과 통제집단의 유아 총 56명을 대상으 로 독립된 공간에서 훈련받은 조사자와 함께 실시되었다. 사 전검사는 네 가지가 이루어지기 때문에 검사 시 순서에 따른 효과를 방지하고자 역균형화(counter-balancing) 방법을 적용 하였으며, 네 개의 검사를 4 일에 걸쳐 진행하였고, 1 회의 검사 실시 시간은 30 분을 넘지 않았다. 수학적 능력 검사와 과학적 능력 검사는 채점 기준에 따라 점수를 부여하여 총점을 산출 하였으며, 창의성 검사와 지능 검사는 검사 후 연구소에 의뢰 하여 표준점수를 산출하였다.

\section{프로그램 실시}

본 연구에서 개발된 프로그램은 2018년 4월 30일 6월 29일 까지 실험집단을 대상으로 유아교육을 전공하고 경력 20년 이상의 아동학 박사 수료생인 본 연구자가 적용하였다. 하루 일과 중 자유선택활동과 대·소 집단활동 시간을 활용하여, 매 주 2 회기씩 총 8 주간 실시하고, 전체 오리엔테이션 1 회기와 전체 평가 1 회기를 포함하여 총 18 회기로 진행하였다. 기존 의 목공놀이 프로그램은 교사가 정해놓은 주제에 맞게 구성물 을 완성하는 목적의 단위 활동으로 계획되어 활동 간의 연계 


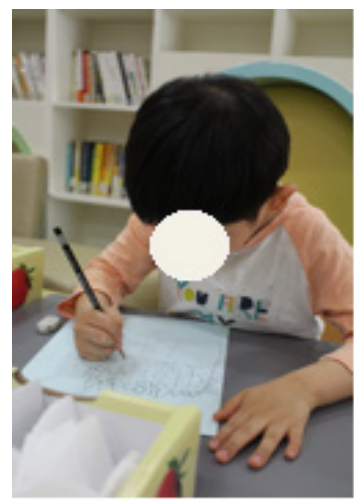

Engagement \& Exploration

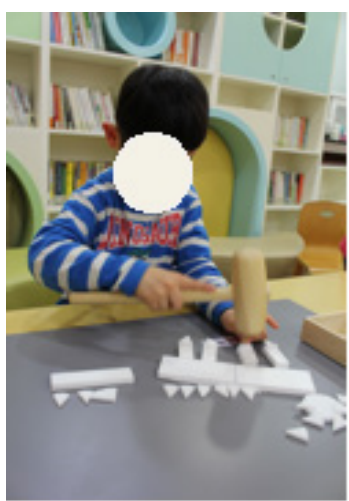

Explanation

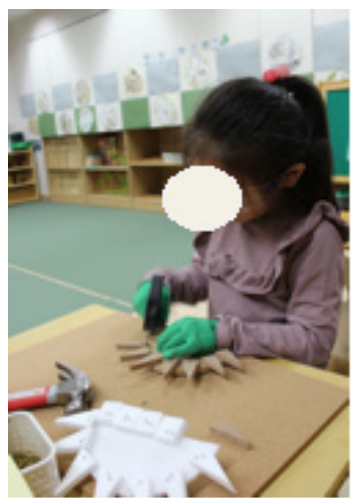

Expansion

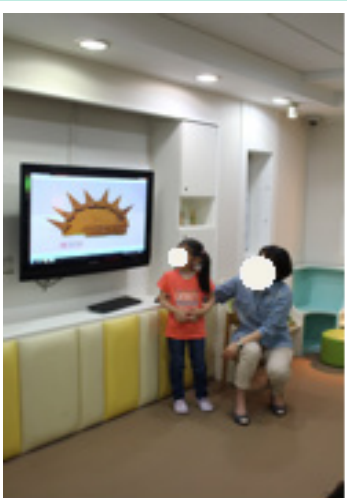

Evaluation

Figure 1. Activity Picture of Set 1.

가 부족하고, 유아 주도의 탐구학습은 이루어지지 못했다. 이 러한 한계점에 주목하여 본 프로그램은 만들고자 하는 대상물 의 주제를 유아들과 함께 정하고, 유아의 주도적인 탐구학습 을 통해 지식을 습득하며, 이와 같은 과정의 반복적 경험을 통 해 지식을 구성해 나갈 수 있도록 차별성을 두어 구성하였다. 이에 유아들이 구성물을 만드는 과정에서 충분히 탐구과정을 경험하고, 다양하고 구성물의 산출과 창의적인 문제해결 방법 모색을 위하여 회기별 소요시간은 개인차를 고려하여 30-60 분으로 계획하였다.

순환학습기반 수과학 통합 유아 목공놀이 프로그램 본 연구에 서 실시된 목공놀이 프로그램은 $5 \mathrm{E}$ 순환학습모델(Gallenstein, 2003)에 기초하였다. 1 회기와 18회기를 제외한 2-17회기는 한 가지 주제(한 세트)가 4 회기 동안 진행된다. 한 세트(4회기)는 $5 \mathrm{E}$ 순환학습단계에 따라 1 회기 참여 및 탐색, 2 회기 설명, 3 회 기 확장, 4 회기 평가로 진행되는데, 참여 및 탐색 단계는 유아 가 스스로 집단활동에 참여하고 다양한 재료(우드락 및 나무 조각)를 탐색하며 친구들과 결정한 공동으로 정한 주제(예: 동 물) 중 자신이 만들고 싶은 구성물(예: 강아지, 악어 등)을 설 계할 수 있도록 하였다. 설명은 자신이 설계한 것에 대해 생각 을 표현하고 설명하는 단계로, 이전 단계의 설계도를 기반으 로 우드락 조각을 활용하여 구성물을 만든다. 확장은 설명 단 계에서 경험한 시행착오를 반영하여, 새로운 아이디어의 창출 과 확장의 단계로 나무 조각을 이용한 구성물을 만든다. 마지 막 단계인 평가는 이전 단계들에서 경험한 과정에 대한 자기 평가와 공유의 시간이 이루어지는 단계로 친구들에게 구성물 을 만든 과정을 소개하고, 친구들과 나눈 평가 내용은 다음 주 제의 구성물 제작에 반영할 수 있도록 구성하였다. 본 프로그
램은 순환학습모델이라는 큰 구조 안에서 교사가 유아와 함께 정한 주제(만들고 싶은 대상물)를 정하고, 유아가 주체가 되 어 제작하고 싶은 구성물을 설계하며, 이에 적합한 자료를 선 택하여 시행착오를 통해 구성물을 만들어 볼 수 있도록 구성 함으로써 반복적이고 순환적인 과정 안에서 수학과 과학의 과 정적 통합을 이루고, 창의성 증진을 도모하고자 하였다. 특히, 본 프로그램은 유아가 구성물을 만들고 문제를 해결하는 과정 에서 수학과 과학의 과정적 통합을 이루고, 다양한 해결방안 을 모색하는 가운데 창의성을 돕고자 하였기 때문에 4 개의 세 트에 차별성(집단크기, 재료의 활용)을 고려하였다. 유아들과 함께 결정한 4 가지의 주제(세트별 1 주제)가 반복하여 진행되 는 16 회기 동안 세트 1,2 는 개별로 구성물을 만들고, 세트 3,4 는 집단으로 구성물을 만들어 볼 수 있도록 구성하였다. 이는 유아 혼자 구성물을 만들 때 발생하는 문제 상황과 또래와 함 께 구성물을 만들 때 발생되는 문제 상황을 경험하고 타인과 의 의사소통을 통해 다양한 대안을 창출해 보는 경험을 제공 하기 위해서였다. 이뿐만 아니라 세트 3은 4집단(7명씩), 세트 4는 2집단(14명씩)으로 차별을 두어 다양한 집단에서 문제해 결의 과정을 경험할 수 있도록 구성하였다. 재료를 활용함에 있어 세트 1 은 준비된 재료 (두께 $1 \mathrm{~cm}$ 의 재단된 나무 조각으로 $20 \times 20,10 \times 10,5 \times 5$ 크기의 정사각형 및 직사각형, 정삼각형 및 직각삼각형, 지름 $5 \mathrm{~cm}, 10 \mathrm{~cm}$ 크기의 원형 및 반원형) 내에서, 세트 2-4는 준비된 재료와 각자 필요한 조각을 직접 재단하여 자신의 설계한 구성물을 제작해 보는 과정에서 수학적 능력, 과학적 사고기술의 활용과 더불어 다양하고 창의적인 문제해 결 방법을 모색하고자 하였다. 또한 개별적으로 구성물을 만 드는 시간을 더 요청하는 경우에는 본 프로그램의 회기가 진 행되지 않는 날이더라도 구성물을 만들 수 있는 시간을 할애 
Table 2

Independent Samples T-Test of Mathematical Ability

\begin{tabular}{|c|c|c|c|c|c|c|}
\hline & \multicolumn{2}{|c|}{ Pre $(n=28)$} & \multirow[b]{3}{*}{$t$} & \multicolumn{2}{|c|}{ Post $(n=28)$} & \multirow[b]{3}{*}{$t$} \\
\hline & Experimental & Control & & Experimental & Control & \\
\hline & $M(S D)$ & $M(S D)$ & & $M(S D)$ & $M(S D)$ & \\
\hline Number and calculation & $11.42(2.97)$ & $12.39(3.33)$ & -1.14 & $14.57(2.41)$ & $12.46(3.39)$ & $2.71^{* *}$ \\
\hline Geometry & $9.96(2.13)$ & $10.50(1.69)$ & -1.04 & $11.86(1.58)$ & $10.57(1.64)$ & $2.99^{* *}$ \\
\hline
\end{tabular}

${ }^{*} p<.05 .{ }^{* *} p<.01$.

해 주었다. 활동의 이해를 위한 1 세트의 활동사진은 Figure 1과 같으며, 순환학습기반 수과학 통합 유아 목공놀이 프로그램은 Appendix 1에 제시하였다.

\section{사후검사}

사후검사는 프로그램 종료 후 2018년 7월 4일 7월 20일 사이 에 사전검사와 동일한 방법으로 실시되었다. 지능검사는 영향 력을 통제하고자 실시하였으므로, 사후검사는 세 가지(수학 적 능력, 과학적 능력, 창의성)만 진행되었다.

\section{자료분석}

자료분석은 SPSS 21.0 (IBM Co., Armonk, NY)을 사용하였으 며, 실험집단과 통제집단의 동질성 검증과 프로그램 처치 이 후 사후 차이를 분석하기 위해 독립표본 $t$-검정을 하고, 프로 그램 실시가 실험집단에 실제적인 변화가 있는지 알아보기 위 해 대응표본 $t$-검정을 하였다.

\section{Results}

\section{순환학습기반 수과학 통합 유아 목공놀이 프로 그램이 유아의 수학적 능력에 미치는 효과}

순환학습기반 수과학 통합 유아 목공놀이 프로그램이 유아의 수학적 능력에 미치는 효과 검증에 앞서 집단 간 동질성 여부 를 검증한 결과는 Table 2 와 같다. Table 2 와 같이 프로그램을 실시하기 전 유아의 수학적 능력에 대한 사전점수와 사후점수 에 대한 평균 및 표준편차를 산출하였으며, 수학적 능력에 대
한 집단 간 차이 검증을 실시한 결과, 대수, 수와 연산, 기하, 측 정, 확률과 통계 점수에서 유의한 차이가 나타나지 않아 이를 통해 두 집단 간 사전 동질성이 확보되었음을 알 수 있다.

프로그램 실시 후 실험집단과 통제집단의 유아의 수학적 능력의 점수 차이를 비교한 결과, 유아의 수학적 능력을 하위 영역별로 살펴보면 대수 $(t=2.17, p<.05)$, 수와 연산 $(t=2.71$, $p<.01)$, 기하 $(t=2.99, p<.01)$, 측정 $(t=2.58, p<.05)$, 확률과 통계 $(t=2.91, p<.01)$ 는 사후점수에서 집단 간 통계적으로 유 의한 차이가 있는 것으로 나타났다. 이와 같은 결과는 프로그 램 실시 전 실험집단과 통제집단의 유아들이 비슷한 수준이었 으나, 프로그램 실시 후 실험집단 유아의 수학적 능력 점수가 통제집단의 유아들에 비해 높아졌음을 나타낸다. 프로그램 실 시가 실험집단 유아의 수학적 능력에 실제적인 효과를 미쳤 는지 추가적으로 확인하기 위해 대응표본 $t$-검정을 실시한 결 과 실험집단의 수학적 능력 하위영역별로 점수를 살펴보면 대 수 $(t=-5.75, p<.001)$, 수와 연산 $(t=-8.26, p<.001)$, 기하 $(t=$ $-4.95, p<.001)$, 측정 $(t=-7.55, p<.001)$, 확률과 통계 $(t=-4.48$, $p<.001)$ 의 모든 영역에서 통계적으로 유의한 차이가 있는 것 으로 나타났다. 통제집단의 수학적 능력 하위영역별 평균이 프로그램 실시 전에 비해 실시 후에 높아진 것을 볼 수 있으나, 이는 통계적으로 유의한 차이를 보이지 않았다.

따라서 순환학습기반 수과학 통합 유아 목공놀이 프로그램 은 유아의 수학적 능력발달에 긍정적인 영향을 미쳤음을 알 수 있다.

\section{순환학습기반 수과학 통합 유아 목공놀이 프로 그램이 유아의 과학적 능력에 미치는 효과}

순환학습기반 수과학 통합 유아 목공놀이 프로그램이 유아의 과학적 능력에 미치는 효과 검증에 앞서 집단 간 동질성 여부 
Table 3

Independent Samples T-Test of Scientific Ability

\begin{tabular}{|c|c|c|c|c|c|c|}
\hline & \multicolumn{2}{|c|}{ Pre $(n=28)$} & \multirow[b]{3}{*}{$t$} & \multicolumn{2}{|c|}{ Post $(n=28)$} & \multirow[b]{3}{*}{$t$} \\
\hline & Experimental & Control & & Experimental & Control & \\
\hline & $M(S D)$ & $M(S D)$ & & $M(S D)$ & $M(S D)$ & \\
\hline Sorting & $3.93(1.02)$ & $4.39(1.07)$ & -1.67 & $7.29(.60)$ & $4.82(1.16)$ & $10.01^{* * *}$ \\
\hline Measurement & $9.50(1.23)$ & $10.11(1.52)$ & -1.64 & $11.82(1.59)$ & $10.04(1.50)$ & $4.32^{* * *}$ \\
\hline Communication & $7.71(1.46)$ & $8.18(1.47)$ & -1.19 & $10.11(.83)$ & $8.54(1.26)$ & $5.50^{* * *}$ \\
\hline Scientific ability & $44.14(4.33)$ & $46.75(5.51)$ & -1.97 & $57.29(5.37)$ & $47.68(5.45)$ & $6.64^{* * *}$ \\
\hline
\end{tabular}

${ }^{* *} p<.01 .{ }^{* * *} p<.001$.

를 검증한 결과는 Table 3과 같다. Table 3과 같이 프로그램을 실시하기 전 유아의 과학적 능력에 대한 사전점수와 사후점수 에 대한 평균 및 표준편차를 산출하였으며, 과학적 능력에 대 한 집단 간 차이 검증을 실시한 결과, 유아의 과학적 능력 총점 은 실험집단 $(M=44.14, S D=4.33)$, 통제집단 $(M=46.75, S D=$ 5.51)은 통계적으로 유의한 차이가 나타나지 않았다. 이러한 결과는 유아의 과학적 능력 모든 하위영역에서 동일하게 나타 났으며, 이를 통해 두 집단 간 사전 동질성이 확보되었음을 알 수 있다.

프로그램 실시 후 실험집단과 통제집단의 유아의 과학적 능력의 점수 차이를 비교한 결과, 유아의 과학적 능력 총점은 실험집단 $(M=57.29, S D=5.37)$ 이 통제집단 $(M=47.68, S D=$ $5.45)$ 보다 높은 것으로 나타났고, 통계적으로 유의한 차이가 있는 것으로 나타났다 $(t=6.64, p<.001)$. 하위영역별로 살펴 보면 관찰하기 $(t=5.50, p<.001)$, 분류하기 $(t=10.01, p<.001)$, 측정하기 $(t=4.32, p<.001)$, 추론하기 $(t=5.51, p<.001)$, 예측 하기 $(t=3.28, p<.01)$, 의사소통하기 $(t=5.50, p<.001)$ 는 사후 점수에서 집단 간 통계적으로 유의한 차이가 있는 것으로 나 타났다. 이와 같은 결과는 프로그램 실시 전 실험집단과 통제 집단의 유아들이 비슷한 수준이었으나, 프로그램실시 후 실 험집단 유아의 과학적 능력 점수가 통제집단의 유아들에 비 해 높아졌음을 나타낸다. 프로그램 실시가 실험집단 유아의 과학적 능력에 실제적인 효과를 미쳤는지 추가적으로 확인 하기 위해 대응표본 $t$-검정을 실시한 결과 실험집단의 프로그 램 실시 전 과학적 능력 총점 $(M=44.14, S D=4.33)$ 에 비해 프 로그램 실시 후 과학적 능력 총점 $(M=57.29, S D=5.37)$ 이 높 은 것으로 나타났고, 통계적으로 유의한 차이가 있는 것으로 나타났다 $(t=-16.50, p<.001)$. 하위영역별로 살펴보면 관찰하
기 $(t=-8.79, p<.001)$, 분류하기 $(t=-16.21, p<.001)$, 측정하기 $(t=-9.20, p<.001)$, 추론하기 $(t=-8.63, p<.001)$, 예측하기 $(t=$ $-8.29, p<.001)$, 의사소통하기 $(t=-9.07, p<.001)$ 의 모든 영역 에서도 동일하게 통계적으로 유의한 차이가 있는 것으로 나 타났다. 통제집단의 프로그램 실시 전 과학적 능력 총점 $(M=$ $46.75, S D=5.51)$ 에 비해 프로그램 실시 후 과학적 능력 총점 $(M=47.68, S D=5.45)$ 이 높아졌으나, 이는 통계적으로 유의 한 차이를 보이지 않았으며, 하위영역 모두에서도 동일한 결 과가 나타났다.

따라서 순환학습기반 수과학 통합 유아 목공놀이 프로그램 은 유아의 과학적 능력발달에 긍정적인 영향을 미쳤음을 알 수 있다.

\section{순환학습기반 수과학 통합 유아 목공놀이 프로 그램이 유아의 창의성에 미치는 효과}

순환학습기반 수과학 통합 유아 목공놀이 프로그램이 유아의 창의성에 미치는 효과 검증에 앞서 집단 간 동질성 여부를 검 증한 결과는 Table 4 와 같다. Table 4와 같이 프로그램을 실시하 기 전 유아의 창의성에 대한 사전점수와 사후점수에 대한 평 균 및 표준편차를 산출하였으며, 창의성에 대한 집단 간 차이 검증을 실시한 결과, 유아의 수학적 능력 총점은 실험집단 $(M$ $=94.93, S D=23.45)$, 통제집단 $(M=98.79, S D=14.87)$ 은 통계 적으로 유의한 차이가 나타나지 않았다. 이러한 결과는 유아 의 창의성 모든 하위영역에서 동일하게 나타났으며, 이를 통 해 두 집단 간 사전 동질성이 확보되었음을 알 수 있다.

프로그램 실시 후 실험집단과 통제집단의 유아의 창의성 점수 차이를 비교한 결과, 유아의 창의성 총점은 실험집단 $(M$ 
Table 4

Independent Samples T-Test of Creativity

\begin{tabular}{|c|c|c|c|c|c|c|}
\hline & \multicolumn{2}{|c|}{ Pre $(n=28)$} & \multirow[b]{3}{*}{$\tau$} & \multicolumn{2}{|c|}{ Post $(n=28)$} & \multirow[b]{3}{*}{$t$} \\
\hline & Experimental & Control & & Experimental & Control & \\
\hline & $M(S D)$ & $M(S D)$ & & $M(S D)$ & $M(S D)$ & \\
\hline Originality & $87.43(25.67)$ & $89.68(14.13)$ & -.41 & $115.71(24.57)$ & $92.00(16.58)$ & $4.23^{* * *}$ \\
\hline Abstractness of titles & $67.57(32.85)$ & $82.21(25.52)$ & 1.78 & $104.29(17.47)$ & $86.82(26.96)$ & $2.88^{* *}$ \\
\hline Creative strengths & $6.60(3.12)$ & $7.60(2.75)$ & -1.27 & $9.75(2.53)$ & $6.89(2.28)$ & $4.43^{* * *}$ \\
\hline Creativity & $94.93(23.45)$ & $98.79(14.87)$ & -.74 & $123.71(14.72)$ & $101.82(15.27)$ & $6.21^{* * *}$ \\
\hline
\end{tabular}

${ }^{* *} p<.01 .{ }^{* * *} p<.001$.

$=123.71, S D=14.72)$ 이 통제집단 $(M=101.82, S D=15.27)$ 보 다 높은 것으로 나타났고, 통계적으로 유의한 차이가 있는 것 으로 나타났다 $(t=6.21, p<.001)$. 하위영역별로 살펴보면 유 창성 $(t=7.23, p<.001)$, 독창성 $(t=4.23, p<.001)$, 제목의 추 상성 $(t=2.88, p<.01)$, 정교성 $(t=4.08, p<.001)$, 성급한 종결 에 대한 저항 $(t=3.83, p<.001)$, 창의적 강점 $(t=4.43, p<.001)$ 은 사후 점수에서 집단 간 통계적으로 유의한 차이가 있는 것 으로 나타났다. 이와 같은 결과는 프로그램 실시 전 실험집단 과 통제집단의 유아들이 비슷한 수준이었으나, 프로그램 실 시 후 실험집단 유아의 창의성 점수가 통제집단의 유아들에 비해 높아졌음을 나타낸다. 프로그램 실시가 실험집단 유아 의 창의성에 실제적인 효과를 미쳤는지 추가적으로 확인하기 위해 대응표본 $t$-검정을 실시한 결과 실험집단의 프로그램 실 시 전 창의성 총점 $(M=94.93, S D=23.45)$ 에 비해 프로그램 실 시 후 창의성 총점 $(M=123.71, S D=14.72)$ 이 높은 것으로 나 타났고, 통계적으로 유의한 차이가 있는 것으로 나타났다 $(t=$ -7.49, $p$ <.001). 하위영역별로 살펴보면 유창성 $(t=-6.09, p<$ $.001)$, 독창성 $(t=-4.28, p<.001)$, 제목의 추상성 $(t=-5.58, p<$ $.001)$, 정교성 $(t=-5.85, p<.001)$, 성급한 종결에 대한 저항 $(t=$ $-4.77, p<.001)$, 창의적 강점 $(t=-6.38, p<.001)$ 의 모든 영역에 서도 동일하게 통계적으로 유의한 차이가 있는 것으로 나타났 다. 통제집단의 프로그램 실시 전 창의성 총점 $(M=98.79, S D$ $=14.87)$ 에 비해 프로그램 실시 후 창의성 총점 $(M=101.82, S D$ = 15.27)이 높아졌으나, 이는 통계적으로 유의한 차이를 보이 지 않았으며, 하위영역 모두에서도 동일한 결과가 나타났다.

따라서 순환학습기반 수과학 통합 유아 목공놀이 프로그램 은 유아의 창의성 발달에 긍정적인 영향을 미쳤음을 알 수 있 다.

\section{Discussion}

본 연구는 순환학습기반 수과학 통합 목공놀이 프로그램이 유 아의 수학적 능력과 과학적 능력 및 창의성 증진에 효과가 있 는지 알아보고자 하였다. 특히 본 프로그램은 구성주의 이론 에 기초하여 수학과 과학의 기본 개념형성과 탐구과정을 촉 진하기 위한 교수학습모형인 순환학습모델을 기반으로 학습 자 스스로 구체적인 경험을 통한 수학적, 과학적 능력 및 창의 적 사고가 발달하도록 구성하였다. 총 18 회기로 1 회기는 오리 엔테이션, 2-17회기는 목공놀이 프로그램, 18 회기는 평가로 계획하였다. 프로그램은 순환학습모델의 $5 \mathrm{E}$ (참여 및 탐색-설 명-확장-평가) 단계를 4 회기의 한 세트로 구성하여 4 개의 구성 물을 제작해 볼 수 있도록 하였다. 프로그램 적용에 대한 결론 은 다음과 같다.

첫째, 순환학습기반 수과학 통합 유아 목공놀이 프로그램 은 유아의 수학적 능력을 증진 시키는데 효과가 있다. 유아의 수학적 능력에 미치는 영향을 구체적으로 살펴보면, 목공놀 이 프로그램을 적용한 실험집단의 유아들이 통제집단의 유아 들보다 수학적 능력인 '대수', ‘수와 연산' '기하', ‘측정', ‘확률 과 통계' 모두에서 유의하게 향상되는 것으로 나타났다. 본 연 구결과는 수과학 통합 활동이 수학적 능력에 긍정적인 영향을 미친다고 보고한 연구들(S. J. Kim, 2001; Koo, 2007; E. J. Lee, 2010; Yun, 2005)과 수학과 관련한 다른 영역과의 통합 활동 이 유아의 수학적 능력 및 수학적 태도에 긍정적인 영향을 미 친다는 연구들(S. Han \& Park, 2016; M.-Y. Kim, Sung \& Hong, 2009; S. Kim \& Shin, 2012)과 일관된다. 예를 들어 '대수'의 경 우 자신이 설계한 악어 등에 있는 비늘을 나타내기 위해 크고 작은 조각을 재단하여 순서대로 붙인다거나, '수와 연산' 이나 
‘측정'의 경우 공동 구성에 필요한 큰 나무의 길이를 알아보기 위해 연필을 몇 번 재어야 하는지 세어보는 모습을 발견할 수 있었다. '기하'의 경우 반복적인 경험을 통해 자신이 필요한 모 양 조각을 찾아 구성하거나, 재단하는 모습을 볼 수 있었고, ‘확률과 통계'의 경우 목공놀이에서 나타나는 문제 상황의 경 향성을 파악하거나 해결방안이나 대안을 모색하려는 시도를 볼 수 있었다. 유아들은 발달 특성상 통합적인 교육경험이 바 람직하며(MEST, 2013), 수학과 과학의 학습 과정이 유사한 과 정적 기술을 공유하고 있어 수학의 성취를 위해 수학과 과학 이 통합되어야 한다고 주장한 바와 같이(American Association for the Advancement of Science, 1999), 수학적 능력의 발달은 목공놀이를 하는 동안 자연스러운 과정적 통합의 결과라고 할 수 있다. 이 뿐만 아니라 본 프로그램은 순환학습을 기반으로 자신이 정한 주제에 따라 설계를 하고, 비구조적인 매체를 필 요에 따라 스스로 재단하여 구성해 보며, 수학적 지식의 습득 과 활용을 반복적으로 경험할 수 있도록 구성하였다. 예를 들 어 수와 연산의 경우 “긴 조각이 없으면 작은 두 개를 연결하 면 되지요. 지난번 동물 만들 때도 긴 조각 대신 작은 조각 두 개를 연결하니까 딱 맞았어요.”라며 반복적인 경험에서 오는 수학적 문제해결 방안을 제시하는 모습을 볼 수 있었다. 이러 한 모습은 유아는 발달 특성상 단일 활동보다는 활동 간 연계 나 통합을 고려한 교수학습방법을 적용한 교육과정 경험 시 수학적 능력에 긍정적인 영향이 있음을 보고한 연구들(Ahn, 2005; J.-H. Kim, 2017; S. H. Kim, 2015; N. R. Park, 2011)과 맥 을 같이 한다. 이처럼 문제를 탐색하고 탐구하여 해결해나가 는 과정의 교수학습방법은 유아가 자율적으로 수학적 지식을 구성할 수 있도록 하여 능숙하게 문제를 해결하는 경험을 제 공하였다. 그러므로 일회적인 단위 활동이 아닌 참여-탐색-설 명-확장-평가의 반복적인 탐구과정을 제공하는 순환학습기반 의 목공놀이 프로그램은 유아의 수학적 능력을 도모했음을 알 수 있다. 이처럼 자발적인 문제해결 과정을 통해 수학적 능력 을 습득할 수 있도록 정해진 재료를 제공하는 것이 아닌 유아 가 필요에 따라 재단하여 재료를 활용함으로써 수와 연산, 측 정, 공간 등의 수학적 능력의 발달을 도운 것은 메이커 교육에 서 제시한 바와 같이 유아를 학습의 주도적인 주체로 인식(Y.

I. Kim, 2018)하는 방향과 맥을 같이한 결과라 할 수 있다.

둘째, 순환학습기반 수과학 통합 유아 목공놀이 프로그램 은 유아의 과학적 능력을 증진 시키는 데 효과가 있다. 유아 의 과학적 능력 하위영역에 미치는 영향을 구체적으로 살펴보 면, 목공놀이 프로그램을 적용한 실험집단의 유아들이 통제 집단의 유아들보다 과학적 능력 하위영역인 '관찰하기', '분류
하기', ‘측정하기', '추론하기', '예측하기', ‘의사소통하기' 모두 에서 유의하게 향상되었다. 본 연구결과는 수과학 통합 활동 이 과학적 능력에 긍정적인 영향이 있음을 보고한 연구들(S. J. Kim, 2001; S. M. Kim \& Ahn, 2008; Koo, 2007; E. J. Lee, 2010; Yun, 2005)과 과학 중심의 통합 활동이 과학적 능력에 미치는 영향을 보고한 연구들(Oh, Woo, Yang, Park, \& Jung, 2009)과 맥을 같이 한다. 유아들은 회기가 진행되어가는 동안 타인의 구성물에도 관심을 가지고 관찰하면서 자신의 구성물과 다른 점도 발견하고, 문제에 대안을 모색하면서 주변을 관찰하고자 하는 태도를 보였으며, 자신이 설계한 구성물을 만들기 위한 나무 조각을 재단하는 과정에서 높이, 길이, 넓이 등의 다양한 측정능력을 활용하는 모습을 볼 수 있었다. 또한 구성물을 반 복적으로 만들어 보는 경험을 통해 문제 상황의 원인을 추론 하고, 이러한 결과를 예측해보는 과정을 경험할 수 있었다. 이 뿐만 아니라 구성물을 만든 과정을 다른 사람들에게 소개하고 평가하는 시간을 통해 의사소통능력의 증진을 도모할 수 있었 다. 유아가 스스로 자발적으로 문제를 발견하고 재료를 다루 어 보며 물체의 특성을 이해하고, 특히 문제해결 과정을 또래 와 공유하는 ‘의사소통하기' 능력의 증진은 메이커 교육에서 지향하는 과정인 자유로운 환경에서 타인과 의사소통을 통해 경험을 공유한 결과(Kang \& Kim, 2017)라고 할 수 있다.

이와 같은 결과는 학습자가 주체가 되어 구성물을 만들어 보는 반복적인 과정에서 문제에 대한 원인, 결과를 예측하고 이를 타인과 공유함으로써 과학적 사고기술이 더욱 증진된 것 이며 탐구 중심 과학 활동에 참여하여 자연물의 구체적 조작 과 직접적인 경험이 과학적 사고에 긍정적인 영향을 미친다 는 연구(Go \& Shin, 2011)와 맥을 같이한다. 또한 유아의 탐구 능력 증진을 위한 교수학습방법 적용이 유아의 수학, 과학적 능력 및 태도에 긍정적인 효과가 있음을 보고한 연구들(Cho, 2015; Jang \& Kim, 2017; K. M. Lee, 2000; H. H. Noh, 2005)의 주장을 뒷받침한다.

셋째, 순환학습기반 수과학 통합 유아 목공놀이 프로그램 은 유아의 창의성 증진에 효과적이다. 유아의 창의성의 하위 영역에 미치는 영향을 구체적으로 살펴보면, 목공놀이 프로 그램을 적용한 실험집단의 유아들이 통제집단의 유아들보다 창의성의 하위영역인 ‘유창성', ‘독창성', ‘제목의 추상성', ‘정 교성', '성급한 종결에 대한 저항', '창의적 강점' 모두에서 유 의하게 향상되는 것으로 나타났다. 본 연구결과는 수과학 통 합 활동이 창의성에 긍정적인 영향이 있음을 보고한 연구들 (Kaon \& Park, 1997; Y. Kim, 2017), 목공놀이가 창의성 발달에 긍정적인 영향이 있음을 보고한 연구들(Hwang, 2003; J. Kim 
\& Jang, 2015)과 같은 맥락이다. 또한 문제해결을 위한 교수학 습방법이 유아의 창의성에 긍정적인 효과가 있음을 보고한 연 구들(Bae, 2010; Baek, 2018; C.-H. Chung, Kim, Kim, \& Choi, 2006; C. H. Chung \& Park, 2004; Y. Kim, 2017; K. H. Lee, Han, $\& \operatorname{Lim}, 2011)$ 의 주장을 뒷받침한다. 본 프로그램은 주제를 정 하고, 주제에 따른 설계와 구성물 제작의 모든 과정을 유아가 주도할 수 있도록 계획하며, 다양한 구성물을 만드는 과정에 서 발생하는 문제 상황에 대한 창의적인 대안을 모색하여 해 결해 볼 수 있는 교수학습방법을 적용했기 때문에 창의성의 모든 요소를 발견할 수 있었다. 이뿐만 아니라 순환학습모델 을 적용하는 가운데 '정교성'이나 '성급한 종결에 대한 저항' 의 경우는 유아들에게 충분한 시간을 제공해 주는 것이 중요 한 요소인데, 프로그램 시간 이외에도 시간을 더 필요로 하는 유아들을 위해 유동적으로 일과를 조율하여 활동에 집중할 수 있도록 하였기 때문에 관련 능력의 신장을 도모할 수 있었다. 이러한 결과는 메이커 교육의 '메이킹(making)'에서 제시한 바 와 같이 자유로운 환경에서 학습자가 주도하여 다양한 대상물 을 활용하여 창의적 산출물을 만들고, 이를 타인과 공유하는 과정(Kang \& Kim, 2017)의 결과라고 할 수 있다.

결과적으로 순환학습모델에 기반한 탐구지향적 교수학습 방법의 적용은 유아의 수학적 능력과 과학적 능력 및 창의성 증진을 도모하였음을 알 수 있다. 본 연구는 기존의 목공놀이 관련 연구들이 회기 간의 연계성이 부족하거나, 탐구과정이 활발히 이루어지지 못하고 있는 한계점을 극복하기 위해 개 발된 프로그램을 적용하여 유아의 수학적 능력과 과학적 능 력 및 창의성 증진에 유의한 효과가 있음을 밝혔다는 점에 의 의가 있다. 또한 본 연구는 유아의 탐구학습과정을 지향하는 순환학습모델을 기반으로 수과학 통합 목공놀이 프로그램의 기초 모델을 제시하고, 프로그램의 수학적 능력, 과학적 능력 및 창의성에 대한 유용성과 효과성을 확인하고자 하였다. 이 뿐만 아니라 기존의 선행연구들에서는 유아의 수학적, 과학적 능력에 대한 지능의 영향력을 통제하지 않아 프로그램의 온전 한 영향력을 확인하는 데 다소 어려움이 있었으나, 본 연구에 서는 지능의 영향력을 통제하여 그 효과를 검증함으로써 순환 학습기반 수과학 통합 유아 목공놀이 프로그램이 유아의 수학 적, 과학적 능력에 미치는 효과를 온전히 확인하였음에 의의 가 있다.

본 연구의 한계점에 기초하여 후속 연구를 제언하면 다음 과 같다. 첫째, 본 연구는 $S$ 시 $S$ 구의 일부 지역 유치원 만 5세 학급을 대상으로 실시되었다. 이에 추후 연구에서는 연구대상 을 다양한 지역, 기관의 유아로 확대할 필요가 있다. 둘째, 본
연구에서는 누리과정을 운영하는 통제집단과의 연구였으나, 추후 연구에는 다른 교수법을 활용하여 목공놀이를 실시하는 집단을 추가한 연구가 진행될 필요가 있다. 셋째, 목공놀이는 수학적 능력, 과학적 능력 및 창의성 이외에도 효과를 살펴볼 수 있는 다른 변인들이 있으므로 후속 연구에서는 다른 변인 의 효과를 살펴볼 수 있는 연구가 필요하다. 넷째, 본 연구에서 수학적, 과학적 능력에 대한 지능의 영향력을 통제하는 방법 으로 정상 범위의 지능을 보이는 유아들을 연구대상으로 선정 하였으나, 추후 연구는 지능 변인을 통계분석에 투입하여 다 른 변인들과의 통계적인 관련성을 적극적으로 살펴볼 필요가 있다. 이러한 한계점에도 불구하고 본 연구는 목공놀이 프로 그램이 수학적 능력과 과학적 능력 및 창의성의 변인들에 미 치는 긍정적인 영향을 밝히는 후속 연구를 유도하고, 유아보 육·교육 현장에서의 목공놀이 활성화를 위한 교육 프로그램 개발의 기초자료를 제공할 것이며, 나아가 미래사회에 필요한 인재 양성에 기여할 메이커 교육(maker education) 프로그램의 사례로 활용될 것이다.

\section{Notes}

This article is a part of the first author's doctoral dissertation. This article was presented at the 2019 Annual Spring Conference of the Korean Association of Child Studies.

\section{Conflict of Interest}

No potential conflict of interest relevant to this article was reported.

\section{References}

\section{In English}

Abraham, C. (2011). Woodworking: A constructive learning center. Texas Child Care Quarterly, 35(3), 1-3.

American Association for the Advancement of Science. (1999). Dialogue on early childhood science, mathematics, and technology education. Washington, DC: AAAS.

Gallenstein, N. L. (2003). Creative construction of mathematics and 
science concepts in early childhood. Olney, MD: Association for Childhood Education International.

Guilford, J. P. (1968). Intelligence, creativity and their educational implications: Beyond similarity. Psychological Review, 97, 3-18.

Martin, D. J. (2012). Elementary science methods: A constructivist approach. Belmont, CA: Wadsworth Cengage Learning.

Piaget, J. (1964). Part I: Cognitive development in children: Piaget development and learning. Journal of Research in Science Teaching, 2(3), 176-186. doi:10.1002/tea.3660020306

Skeen, P., \& Anita, P. G. (1984). Woodworking for young children. Washington, DC: NAEYC.

Torrance, E. P. (1963). Education and the creative potential. Minneapolis, MN: University of Minnesota Press.

Usiskin, Z., Reys, B. J., \& Reys, R. E. (2014). We need another revolution: Five decades of mathematics curriculum papers. Reston, VA: National Council of Teachers of Mathematics.

\section{In Korean}

Ahn, G.-S. (2005). The development and effectiveness of the integration of mathematics and science education program related to the learning cycle and play. Korea Journal of Child Care and Education, 42, 99-133.

Bae, M. (2010). The influence of carpentry in emergent curriculum for spatial perception ability and prosocial behavior of children (Master's thesis). Retrieved from http://www.riss.kr/ link?id=T12169297

Baek, S. S. (2018). Development and application effect of a Creative Problem Solving (CPS) model-based young children's mathematics education program (Doctoral dissertation). Retrieved from http://www.riss.kr/link?id=T14737069

Cho, H. J. (2015). Development of the early childhood scientific inquiry abilities assessment tool (Doctoral dissertation). Retrieved from http://www.riss.kr/link?id=T13737245

Choi, H.-J., \& Hwang, H.-I. (2003). The development of a mathematical ability test for young children. Journal of Early Childhood Education, 23(4), 273-295.

Choi, H.-J., \& Hwang, H.-I. (2007). The development of a pictorial math ability test for young children. Early Childhood Education Research \& Review, 11(1), 157-180.

Choi, H.-J., \& Lee, H.-E. (2005). The effects of learner variables and home environment on the development of mathematical ability. Journal of Early Childhood Education, 25(2), 27-46.

Choi, H. S., \& Hwang, S. Y. (2010). Exploring educational possibility of the attention deficit hyperactivity: based on the math problem solving ability of ADHD students with medication. Journal of Emotional \& Behavioral Disorders, 26(3), 301-318.
Chung, C.-H., Kim, S.-Y., Kim, H.-N., \& Choi, H. J. (2006). The effects of mathematics instruction based on learning cycle model on preschool children's creativity and mathematical concept. Korea Journal of Child Care and Education, 47, 263-283.

Chung, C. H., \& Park, Y. B. (2004). The effectiveness of the learning cycle model for science instruction: Preschool children's creativity and scientific problem solving ability. Korean Journal of Child Studies, 25(3), 1-14.

Go, O.-S., \& Shin, L.-H. (2011). The effect of nature experiencing woodwork on children's scientific problem-solving abilities. Korea Journal of Child Care and Education, 66, 109-125.

Han, S. S., \& Bae, Y. O. (2004). The effects of integrated activities focused on scientific theme on children's scientific problem solving abilities. Korean Journal of Child Education and Care, 4(2), 1-17.

Han, S., \& Park, Y. (2016). Effects of the activities integrating mathematics and role-play on preschooler's mathematical concept formation and learning motivation. The Korean Journal of Educational Methodology Studies, 28(1), 77-102. doi: 10.17927/tkjems.2016.28.1.79

Hong, H.-K. (2004). Yua suhakneungryeok baldalkwakyoyuk [유아 수학능력 발달과 교육]. Seoul: Yangseowon.

Hong, H.-K. (2005). The integration of science and mathematics in early childhood education. Early Childhood Education Research \& Review, 9(4), 153-169.

Hwang, U.-D. (2003). Effect of woodworking activities on children's creativity and cognitive style (Master's thesis). http://www. riss.kr/link?id=T8999012

Jang, S.-H., \& Kim, J.-H. (2017) A study on the development and application of dietary education program based on learning cycle model for young children. Korean Journal of Child Care \& Education Policy, 11(2), 115-147. doi:10.5718/ kcep.2017.11.2.115

Jeon, K.-W. (2000). Preschoolers' development of creativity with Korean Comprehensive Test for Young Children (K-CCTYC). The Journal of Creativity Education, 3(1), 29-53.

Kaon, Y. R. (1999). Yuarul wihan kyosu-haksubbangbubui ehae [유 아를 위한 교수-학습방법의 이해]. Seoul: Yangseowon.

Kaon, Y. R., \& Park, Y. C. (1997). The effects of creative thinking on activities intergrating math and science. The Journal of Korea Open Association for Early Childhood Education, 2(1), 121-136.

Kang, I. A., \& Kim, H. S. (2017). Exploring the value of the maker mind set at maker education. The Journal of the Korea Contents Association, 17(10), 250-267. doi:10.5392/ JKCA.2017.17.10.250

Kim, J., \& Jang, Y. (2015). The effects of constructive play using unstructured play materials on young children's playfulness and creativity. Journal of Parent Education, 7(2), 15-32. 
Kim, J. H. (2017). A comparison of the effects of the woodworking play and the drawing activity on children's space perceptual ability, language ability and pro-sociality (Doctoral dissertation). Retrieved from http://www.riss.kr/ link?id=T14428787

Kim, J.-H. (2017). The effect of STEAM-Based mathematical education activity on young children's mathematical problemsolving ability and creativity (Master's thesis). Retrieved from http://www.riss.kr/link?id=T14744385

Kim, J. H., \& Kim, J. H. (2018). A study on the relationship between young children's mathematical abilities, scientific abilities and intelligence. Korean Journal of Child Education and Care, 18(4), 199-211. doi:10.21213/kjcec.2018. 18.4.199

Kim, J. H., \& Kim, J. H. (2019). A study on creativity according to young children's gender and intelligence. Journal of Korean Child Care and Education, 15(1), 15-35. doi:10. 14698/jkcce.2019.15.01.015

Kim, M.-Y., Sung, Y.-J., \& Hong, H.-K. (2009). The effects of integrated activity with music and mathematics on spatial abilities and musical aptitude of preschoolers. The Journal of Korea Open Association for Early Childhood Education, 14(4), 393-413.

Kim, S., \& Shin, C. (2012). Effects of math and art activities integration on young children's understanding of geometrical concepts and mathematical attitude. Educational Research, 32, 1-22.

Kim, S. H. (2015). The development and effect of integrated mathematics-science education program using natural objects for young children (Doctoral dissertation). Retrieved from http://www.riss.kr/link?id=T14026866

Kim, S. H. (2015). (Kyosu-hak mohyungkwa bangbubul whalyonghan) Yuawkahakkyoyuk [(교수-학습 모형과 방 법을 활용한) 유아과학교육]. Seoul: hakjisa.

Kim, S. J. (2001). The effect of integrated kindergarten mathematics and science activities on children's inquiry development in mathematics and science. Journal of Future Early Childhood Education, 8(1), 173-203.

Kim, S. M., \& Ahn, J. K. (2008). The effects of family related mathematical inquiry activities based on daily experiences on the young children's mathematical abilities. Korean Journal of Human Ecology, 17(5), 821-833.

Kim, Y. (2017). A study on developing the entrepreneurship through maker education in higher education (Doctoral dissertation). Retrieved from http://www.riss.kr/link?id=T14566936

Kim, Y. C. (1999). Changijuk miujehaekyeol: Changireok eron, gebalkwa suup [창의적 문제해결: 창의력의 이론, 개발 과 수업]. Seoul: Kyoyukkwahaksa.

Kim, Y.-I. (2009). Study of educational values about woodworking in school. Journal of the Korea Furniture Society, 20(4), 253-
261.

Kim, Y.-I. (2018). Exploring the applicability of maker education theory to practical arts education at elementary school. The Journal of Practical Arts Education Research, 24(2), 39-57. doi:10.29113/skpaer.2018.24.2.039

Koo, H. H. (2007). The effect of integrated mathematics and science activities on measuring ability and problem-solving ability of young children (Master's thesis). Retrieved from http://www. riss.kr/link?id=T11066363

Kwon, J. Y., \& Hwang, I. J. (2013). The effects of nonviolent communication program for young children on children's peer competence and empathy. International Journal of Early Childhood Education, 33(1), 361-387. doi:10.18023/ kjece.2013.33.1.018

Lee, E. J. (2010). Effects of mathematics and science integration activity on infant's mathematical ability and interest (Master's thesis). Retrieved from http://www.riss.kr/ link?id=T11966886

Lee, E.-Y. (2010). The effects of mathematical activities through role-play on young children's mathematical concepts. Early Childhood Education Research \& Review, 14(2), 193-215.

Lee, K. H., Han, N. J., \& Lim, K. H. (2011). The effect of CPS science program on the improvement of children's creativity and scientific knowledge. Korean Society for Creativity Education, 11(1), 51-68.

Lee, K. M. (2000). A study of the effect of science education based on the interactive approach on preschool children's scientific concepts, process skills, and attitude (Doctoral dissertation). Retrieved from http://www.riss.kr/link?id=T8546833

Lee, Y. H., \& Won, E. S. (2010). Development of a step-by-step woodcraft activity teaching model for toddlers and its effects. Journal of Future Early Childhood Education, 17(1), $1-19$.

Ministry of Education, Science and Technology. (2013). 3-5se younryeongbyeol nurigwajeong haeseolsuh [3-5세 연령별 누 리과정 해설서]. Seoul: Ministry of Education, Science and Technology Ministry of Health and Welfare.

Ministry of Education. (2016). Kkumgwa haengbogeul wihan gwahakgyoyuk silhyeon 'gwahakgyoyukjonghapgyehoek' [꿈 과 행복을 위한 과학교육 실현 '과학교육종합계획']. Retrieved from MOE website: http://happyedu.moe.go.kr

Mun, S. B. (2014). KABC-II Jeonmunjajichimsuh [KABC- II 전문 가 지침서]. Seoul: Inssait.

Noh, E. H. (2008). A study on the operation conditions of science education in early childhood which teachers perceiving. Korean Journal of Child Education and Care, 8(3), 67-83.

Noh, H. H. (2005). The effect of inquiry-oriented scientific activities on young children's scientific process skills and creativity (Master's thesis). Retrieved from http://www.riss. $\mathrm{kr} /$ link?id=T10431196 
Oh, I. J., \& Kim, J. H. (2019). The effect of a learning cycle modelbased teacher education program on the improvement of mathematics activities using natural objects by early childhood teachers. The Korean Journal of Human Development, 26(3), 17-50. doi:10.15284/kjhd.2019.26.3.17

Oh, Y.-H., Woo, S.-K., Yang, Y.-J., Park, Y.-J., \& Jung, M.A. (2009). The effects of self-directed and integrated science activity on young children's mathematical attitude, problem-solving ability, and scientific attitude. Early Childhood Education Research \& Review, 13(3), 290-311.

Park, H. N. (2010). A study on the influence of young children's woodwork play upon the development of their spatial ability and sociality (Master's thesis). Retrieved from http://www. riss.kr/link?id=T12152674

Park, N. R. (2011). The effects of the learning cycle model-based curriculum modification on the development of mathematical abilities and mathematical process skills of preschoolers with disabilities in inclusive settings (Doctoral dissertation). Retrieved from http://www.riss.kr/link?id=T12469934

Yun, E. K. (2005). The effects of integrated mathematics and science activities on mathematical and scientific attitude of young children (Master's thesis). Retrieved from http://www.riss. $\mathrm{kr} /$ link?id=T10218786

\section{ORCID}

Junhee Kim http://orcid.org/0000-0002-5438-2812

Jihyun Kim http://orcid.org/0000-0001-7263-3008

Received June 28, 2019

Revision received August 14, 2019

Accepted November 7, 2019 


\section{Appendix 1}

A Math-Science Integrating Woodwork Play Program Based on the Learning Cycle

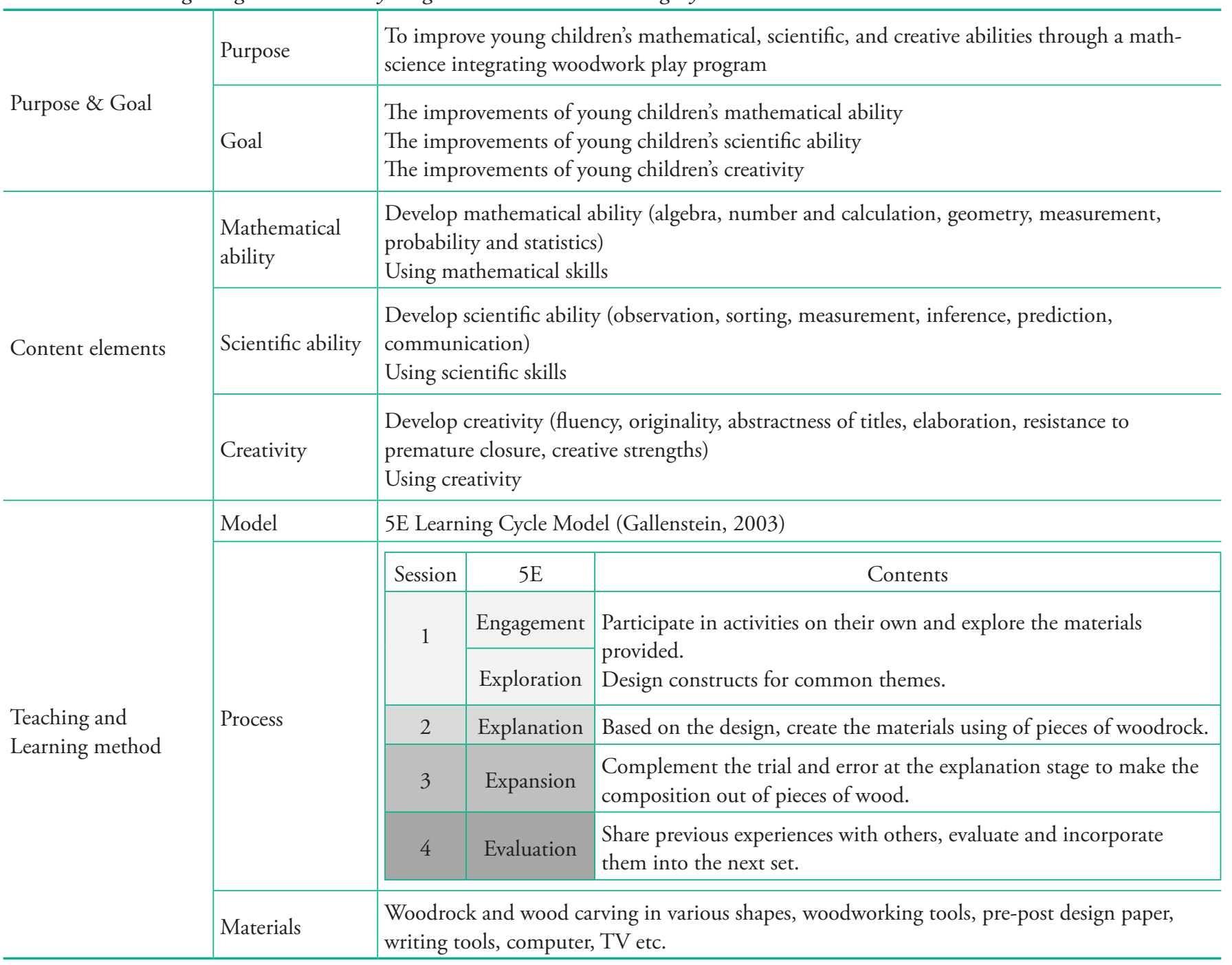

